Check for updates

Cite this: New J. Chem., 2020, 44,14161

Received 13th April 2020 Accepted 22nd July 2020 DOI: $10.1039 / d 0 n j 00403 k$

rsc.li/njc

\title{
Bright neodymium complexes for efficient near infra-red organic light emitting diodes $\dagger$
}

\author{
Zubair Ahmed, (D)*ab Harold C. Avila, ${ }^{\text {ac }}$ Rafael S. Carvalho, ${ }^{a}$ Jiang Kai, ${ }^{d}$ \\ J. A. L. C. Resende, ${ }^{e}$ Elisa Bandini, (D) ${ }^{b}$ Andrea Barbieri (D) ${ }^{* b}$ and \\ Marco Cremona (iD *a
}

\begin{abstract}
This paper reports the synthesis, structures, photophysics and optoelectronics of three NIR-emitting ternary neodymium tris $\beta$-diketonate complexes, $\left[\mathrm{Nd}(\mathrm{hfpd})_{3}(\mathrm{~L})_{n=1-2}\left(\mathrm{H}_{2} \mathrm{O}\right)_{x=0-2}\right]\left(\mathrm{H}_{2} \mathrm{O}\right)_{y=0-1}(\mathrm{hfpd}=$ anionic form of 1,1,1,5,5,5-hexafluoropentane-2,4-dione; $L=$ diphenyl sulfoxide (dpso), $n=1, x=2, y=1$ (1); $\mathrm{L}=$ dibenzyl sulfoxide (dbso), $n=1, x=1, y=0$ (2); $\mathrm{L}=$ triphenyl phosphine oxide (tppo), $n=2, x=0$, $y=0$ (3)). The complexes were used as active components in emitting layers to fabricate NIR-OLEDs with multilayered structures: ITO/MoO $3(2 \mathrm{~nm}) / \beta$-NPB $(30 \mathrm{~nm}) / \mathrm{TcTa}$ :[Nd-complex] $(20 \mathrm{~nm}) / \mathrm{TPBi}:[\mathrm{Nd}$-complex] $(10 \mathrm{~nm}) / \mathrm{TPBi}(10 \mathrm{~nm}) / \mathrm{Alq}_{3}(40 \mathrm{~nm}) / \mathrm{LiF}(0.1 \mathrm{~nm}) / \mathrm{Al}(100 \mathrm{~nm})$. The performance of the present devices is on a par with the best $\mathrm{Nd}$ complex based devices reported so far.
\end{abstract}

\section{Introduction}

Near infra-red (NIR) emitting materials are attracting considerable attention due to their various potential applications in biomedical assay and imaging, ${ }^{1}$ optical fibers, telecommunication and laser systems, ${ }^{2}$ and organic light emitting diodes (OLEDs). ${ }^{3,4}$ The $\mathrm{Nd}(\mathrm{III})$ ion, in particular, with its strong emission at $1.064 \mu \mathrm{m}$, has become an ideal candidate for laser transitions. ${ }^{5}$ On the other hand, its application in the fabrication of NIR-OLEDs is still scarce.

The photoluminescence in the lanthanide (Ln) complexes is usually quenched in the presence of high energy oscillators (C-H, O-H and $\mathrm{N}-\mathrm{H}$ bonds), due to efficient vibronic coupling with the ground state, while substitution with deuterated or fluorinated ligands suppresses the deactivation of the excited states. ${ }^{6-9}$ The fluorinated $\beta$-diketone ligands have proved to be useful antennae leading to highly efficient Ln complexes. ${ }^{6-13}$ Fluorination on $\beta$-diketone also increases the volatility of the respective complexes, a desirable feature for the preparation of

\footnotetext{
${ }^{a}$ Department of Physics, Pontificia Universidade Católica do Rio de Janeiro, PUC-Rio, Rio de Janeiro, RJ 22453-970, Brazil. E-mail: cremona@fis.puc-rio.br

${ }^{b}$ Istituto per la Sintesi Organica e la Fotoreattività (ISOF), Consiglio Nazionale delle Ricerche (CNR), Bologna 40129, Italy. E-mail: andrea.barbieri@isof.cnr.it ${ }^{c}$ Physics Program, Universidad del Atlántico, Puerto Colombia, Atlántico, Colombia

${ }^{d}$ Department of Chemistry, Pontifícia Universidade Católica do Rio de Janeiro, PUC-Rio, Rio de Janeiro, RJ 22453-970, Brazil

${ }^{e}$ Instituto de Ciências Extas e da Terra, Centro Universitário do Araguaia, Universidade Federal do Mato Grosso, 78600-000, Barra do Garças, MT, Brazil $\dagger$ Electronic supplementary information (ESI) available. CCDC 1881479-1881481. For ESI and crystallographic data in CIF or other electronic format see DOI: 10.1039/d0nj00403k
}

optoelectronic devices in controlled high vacuum processing. These results have made such complexes strong candidates as active materials for electroluminescent devices, luminescent resins and liquid crystals. ${ }^{14}$ These complexes usually crystallize as hydrated Ln tris $\beta$-diketonates when Ln ions and $\beta$-diketone are taken in the ratio of $1: 3$. The water molecules in the inner coordination sphere could be replaced by the addition of $\mathrm{N}$ - or O-donor ancillary ligands that deactivate the non-radiative quenching processes, and make the resulting ternary lanthanide complexes relatively more luminescent. ${ }^{10-12,15-17}$

Selection of the N-/O-donor ligands based on their electronic structures, hapticity $\left(\eta_{1-3}\right)$ and coordination ability is a key way to tune the photophysical properties of their respective ternary Ln tris $\beta$-diketone complexes. ${ }^{10-12,14,18-22}$ For instance, Ln complexes with different coordination numbers ( 7 to 9) have been reported to possess asymmetric coordination geometries such as monocapped octahedron (7-coordinate, $C_{3 \mathrm{v}}$ ), trigonaldodecahedron (8-coordinate, $D_{2 \mathrm{~d}}$ ) and monocapped square antiprism (9-coordinate, $C_{4 \mathrm{v}}$ ). ${ }^{10-12}$ Among them, the 7-coordinate complexes were considered to be more asymmetric followed by the 9-coordinate ones. ${ }^{12}$ In contrast, Lima and Simas ${ }^{23}$ predicted highly asymmetric coordination structures of 8-coordinate Ln $\beta$-diketone complexes using two different ancillary ligands in the same coordination sphere. The above-mentioned complexes have shown high luminescence efficiencies, supporting the fact that the 8- or 9-coordinate complexes are more asymmetric/luminescent if they have been produced by using a monodentate ligand. The O-donor ligands such as aryl sulphoxide and phosphine oxide are monodentate, with a low symmetry point group, $C_{n}$, and their coordination to the hydrated Ln chelate moiety is believed to deliver highly 
asymmetric ternary complexes, which in turn are expected to be highly luminescent. Based on such a background, an investigation of 8- or 9-coordinate Ln complexes produced by these monodentate ligands, together with fluorinated $\beta$-diketones, is expected to contribute to the development of luminescent Ln coordination chemistry, which is very useful for further advancement in the OLED industry.

Recently, the Nd(III) complexes with different organic chromophores have been used to fabricate NIR-OLEDs. For instance, 9-hydroxyphenalenone was used to synthesize a $\mathrm{Nd}$ complex of $\left[\mathrm{Nd}(9 \text {-hydroxyphenalen-1-one })_{3}\right]$, which was then doped in poly( $N$-vinylcarbazole) (PVK) to fabricate a polymer NIR-OLED. The device showed a maximum irradiance of $0.85 \mu \mathrm{W} \mathrm{cm}{ }^{-2}$ and an EQE of $0.007 \% .^{24,25}$ Zhang's group fabricated a NIR-OLED based on the $\left[\mathrm{Nd}(\mathrm{PM})_{3}(\mathrm{TP})_{2}\right]$ complex, which gave a maximum irradiance of $0.21 \mu \mathrm{W} \mathrm{cm}{ }^{-2}$ (PM = 1-phenyl-3-methyl-4-isobutyryl5-pyrazolone and $\mathrm{TP}=$ triphenyl phosphine oxide). ${ }^{26} \mathrm{~A} \mathrm{Nd}$ complex, using $\mathrm{Nd}\left[\mathrm{N}\left(\mathrm{SiMe}_{3}\right)_{2}\right]_{3}$ and a bidentate $\mathrm{N}, \mathrm{O}$ ligand, was synthesized and its NIR-OLED was fabricated, which gave a radiant efficiency of $0.82 \mathrm{~mW} \mathrm{~W}^{-1} \cdot{ }^{27}$ Recently, a good performing NIR-OLED device based on the $\left[\mathrm{Nd}(\mathrm{PND})_{3}\right]$ complex was reported, which showed a maximum irradiance of $25 \mu \mathrm{W} \mathrm{cm}{ }^{-2}$ and an EQE of $0.019 \%$ (PND = 6-(pyridin-2-yl)-1,5-naphthyridin-4-ol). ${ }^{28}$ In 2019, a $\mathrm{Nd}$ complex, $\left[\mathrm{Nd}(\mathrm{tta})_{3}(\mathrm{phen})\right]$, based device was reported with an EQE of $0.034 \%(\mathrm{tta}=$ thenoyl trifluoroacetone and phen $=1,10$-phenanthroline) ${ }^{29}$ Considering the performances of the above mentioned devices, more efficient devices are still needed to be designed and fabricated to meet the requirements of practical applications.

This paper reports the synthesis, structures, and photophysical and optoelectronic properties of NIR-emitting ternary neodymium tris $\beta$-diketonate complexes (Chart 1), $\left[\mathrm{Nd}(\mathrm{hfpd})_{3^{-}}\right.$$\left.(\mathrm{L})_{n=1-2}\left(\mathrm{H}_{2} \mathrm{O}\right)_{x=0-2}\right] \cdot\left(\mathrm{H}_{2} \mathrm{O}\right)_{y=0-1}(\mathrm{hfpd})=$ anionic form of 1,1,1,5,5,5hexafluoropentane-2,4-dione, $\mathrm{L}=$ diphenyl sulfoxide (dpso), $n=1, x=2, y=1$ (1); L = dibenzyl sulfoxide (dbso), $n=1$, $x=1, y=0(2) ; \mathrm{L}=$ trisphenyl phosphine oxide (tppo), $n=2, x=0$, $y=0$ (3). Very recently, complex 3 has been reported with a crystal structure and a photoluminescence spectrum only. ${ }^{30}$ Here, we also reported the details of the NIR photophysical properties (solution and solid state) and of the electroluminescence of complex 3, including the crystal structure and NMR studies.

The single crystal X-ray analysis indicates that complex 1 is nona-coordinate with a square antiprismatic $\left(D_{4 \mathrm{~d}}\right)$ geometry, while complexes 2 and 3 are octa-coordinated with a monocapped square antiprism $\left(C_{4 \mathrm{v}}\right)$ geometry. The photophysical properties of the complexes in solution and their PMMA doped

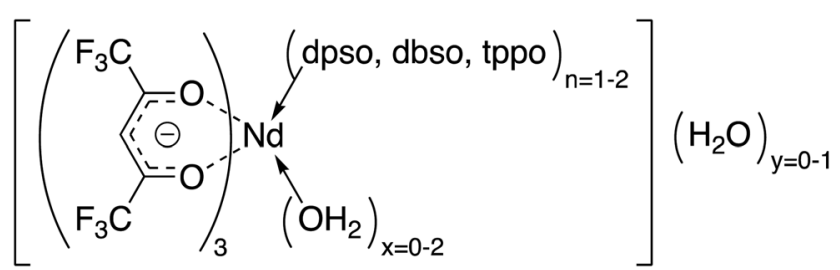

Chart 1 Schematic structures of complexes 1-3. (1) $L=d p s o, n=1, x=2$, $y=1 ;(2) \mathrm{L}=$ dbso, $n=1, x=1, y=0 ;(3) \mathrm{L}=$ tppo, $n=2, x=0, y=0$. films were studied and presented. Finally, the NIR-OLEDs were fabricated with three-layered structures: $\mathrm{ITO} / \mathrm{MoO}_{3}(2 \mathrm{~nm}) / \beta-\mathrm{NPB}$ (30 nm)/TcTa:[complexes 1-3] (20 nm)/TPBi:[complexes 1-3] $(10 \mathrm{~nm}) / \mathrm{TPBi}(10 \mathrm{~nm}) / \mathrm{Alq}_{3}(40 \mathrm{~nm}) / \mathrm{LiF}(0.1 \mathrm{~nm}) / \mathrm{Al}(100 \mathrm{~nm})$, using the present complexes as emitting layers (with complex $\mathbf{1}=$ Device 1; complex 2 = Device 2 and complex 3 = Device 3 ).

\section{Results and discussion}

\section{Synthesis and characterization}

An in situ reaction of ethanol solutions of Hhfpd, L (dpso, dbso, and tppo), $\mathrm{LnCl}_{3} \cdot 6 \mathrm{H}_{2} \mathrm{O}$ and $28 \%$ aqueous $\mathrm{NH}_{3}$ solution in a $3: 1: 1: 3$ molar ratio was performed at room temperature that yielded the eight- and nine-coordinate complexes 1-3 (Scheme 1). The resulting complexes were obtained in good yields $(>80 \%)$. The success of the reaction was authenticated by an immediate formation of a white precipitate of $\mathrm{NH}_{4} \mathrm{Cl}$ in the solution, as soon as all the reactants were mixed. The white precipitate, $\mathrm{NH}_{4} \mathrm{Cl}$, was characterised as it was soluble in water and thermally stable showing no melting point up to $300{ }^{\circ} \mathrm{C}$.

\section{Thermal analysis}

The DSC, TGA and DTG results of complexes 1-3 are shown in Fig. 1. The TG curves of complexes 1 and 3 show two steps of weight loss. Complex 1 shows $3.61 \%$ and $82 \%$ weight loss corresponding to the removal of coordinated water molecules (calc. $\sim 3.5 \%$ ) and the decomposition and volatilisation of the

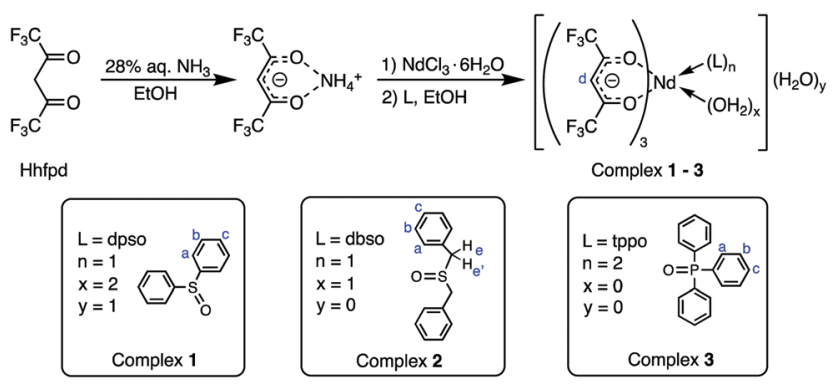

Scheme 1 Synthesis of complexes 1-3.

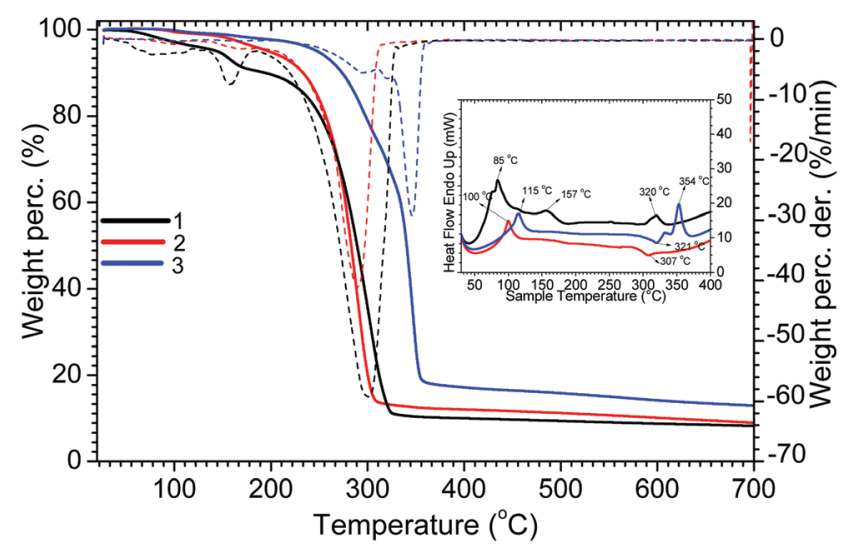

Fig. 1 DSC (inset), TGA (full line) and DTA (dotted line) curves of the complexes, 1-3 
complex, respectively, while complex 3 shows 40.9 and $48.1 \%$ weight loss corresponding to the removal of tppo molecules (calc. $\sim 40.6 \%$ ) and the decomposition and volatilisation of the complex. Complex 2 shows $92.3 \%$ weight loss corresponding to its decomposition and volatilisation. The melting points of complexes 1-3 are 85, 102, and $115{ }^{\circ} \mathrm{C}$, respectively, with initial decomposition temperatures of 194,155 and $174{ }^{\circ} \mathrm{C}$.

\section{Single crystal X-ray crystallography}

The single crystal structures of the complexes 1-3 were solved using the single crystal XRD method, and the main crystal data are given in Table 1 . Complexes $\mathbf{1}$ and $\mathbf{2}$ crystallize in the $P \overline{1}$ space group of the triclinic system while complex 3 crystallizes in the $P 2_{1} / c$ space group of the monoclinic system. All the complexes show a centrosymmetric symmetry. The complexes are mononuclear neutral species, and their unit cells consist of only one crystallographic moiety (Fig. 2). The crystal packing of the complexes satisfies the criterion of minimum energy migration between metal ions since the $\mathrm{Nd}-\mathrm{Nd}$ distances are greater than $8 \AA^{15}$

Complex $\mathbf{1}$ is a nona-coordinate complex where the $\mathrm{Nd}$ ion is coordinated to nine O-atoms: six from three bidentate hfpd anions, one from one monodentate dpso ligand and two from two water molecules. Complex 2 is an octa-coordinate complex as the $\mathrm{Nd}$ ion is coordinated to six O-atoms of three hfpd and two O-atoms, one from the dbso ligand and one from a water molecule. Similarly, complex $\mathbf{3}$ is octa-coordinate wherein the $\mathrm{Nd}$ ion is coordinated to six O-atoms of three hfpd and two O-atoms of two tppo ligands. Both complexes form coordination polyhedra as $\mathrm{NdO}_{8}$. Complex 1 has two coordinated water molecules and one uncoordinated molecule held in the crystal lattice. Complex 2 has only one coordinated water molecule while the inner coordination sphere of complex 3 is free from water molecules. Among complexes 1-3, only complex 3 shows $C_{2}$ crystallographic symmetry with a two-fold axis passing through the $\mathrm{Nd}$ ion and bisecting one of the hfpd units. Moreover, no axis (real or approximate) of three or higher order is shown by the complexes. The average length of the $\mathrm{Nd}-\mathrm{O}\left(\mathrm{H}_{2} \mathrm{O}\right)$ bond in complex 1 is 2.508(3) $\AA$, and this agrees well with that reported for $\mathrm{Nd}-\mathrm{O}\left(\mathrm{H}_{2} \mathrm{O}\right)$ in $\left[\mathrm{Nd}(\mathrm{hfpd})_{3}(\mathrm{bpy})\left(\mathrm{H}_{2} \mathrm{O}\right)\right]$. 0.5bpy (2.542(3) $).{ }^{31}$ The average length of $\mathrm{Nd}-\mathrm{O}(\mathrm{hfpd})$ bonds in the complexes shows little difference, ranging from 2.429 to 2.473(3) $\AA$, and this is in good agreement with that reported for $\left[\mathrm{Nd}(\mathrm{hfpd})_{3}(\mathrm{bpy})\left(\mathrm{H}_{2} \mathrm{O}\right)\right] \cdot 0.5 \mathrm{bpy}(2.460(3) \AA)$. The length of the $\mathrm{Nd}-\mathrm{O}($ tppo) bond in complex 3 is 2.3652(17) $\AA$ and it is shorter than that reported for $\left[\mathrm{Nd}(\mathrm{TTA})_{3}(\mathrm{tppo})_{2}\right](2.410 \AA){ }^{32}$ This could be related to the strong -I effect of the six F-atoms on the hfpd ligand, as compared to that of the three F-atoms on the TTA ligand, which decreases the electron density on coordinated O-atoms of hfpd, which in turn increases the residual acidity of $\mathrm{Nd}(\mathrm{III})$ for the incoming co-ligands. In contrast, the lengths of $\mathrm{Nd}-\mathrm{O}(\mathrm{dpso})$ and $\mathrm{Nd}-\mathrm{O}(\mathrm{dbso})$ bonds in 1 and 2 are 2.439(2) and 2.371(3) A, respectively, and they lie within the range that is observed for $\mathrm{Nd}-\mathrm{O}$ (tppo) bonds in complex 3.

The polytopal analysis method was used to determine the geometry of the coordination structures of the complexes. The coordination polyhedra of the present complexes are shown in Fig. S1 (ESI $\dagger$ ), and the relevant dihedral lengths and angles are

Table 1 Crystal data and structure refinement for complexes 1-3

\begin{tabular}{|c|c|c|c|}
\hline & 1 & 2 & 3 \\
\hline Empirical formula & $\mathrm{C}_{27} \mathrm{H}_{17} \mathrm{~F}_{18} \mathrm{NdO}_{9} \mathrm{~S} \cdot \mathrm{H}_{2} \mathrm{O}$ & $\mathrm{C}_{29} \mathrm{H}_{19} \mathrm{~F}_{18} \mathrm{NdO}_{8} \mathrm{~S}$ & $\mathrm{C}_{51} \mathrm{H}_{33} \mathrm{~F}_{18} \mathrm{NdO}_{8} \mathrm{P}_{2}$ \\
\hline Formula weight & 1021.72 & 1013.74 & 1321.95 \\
\hline Temperature/K & $293(2)$ & $293(2)$ & $293(2)$ \\
\hline Crystal system & triclinic & triclinic & monoclinic \\
\hline Space group & $P \overline{1}$ & $P \overline{1}$ & $P 2_{1} / c$ \\
\hline$a / \AA$ & $11.6815(11)$ & $10.0548(8)$ & $13.1817(7)$ \\
\hline$b / \AA$ & $12.1673(11)$ & $13.6467(12)$ & $13.6362(6)$ \\
\hline$c / \AA$ & $15.3934(15)$ & $14.5545(13)$ & $30.7235(16)$ \\
\hline$\alpha /^{\circ}$ & $69.140(4)$ & $103.029(4)$ & 90 \\
\hline$\beta /^{\circ}$ & $86.876(4)$ & $93.009(4)$ & $90.6330(18)$ \\
\hline$\gamma /^{\circ}$ & $67.194(4)$ & $101.760(4)$ & 90 \\
\hline Volume $/ \AA^{3}$ & $1875.8(3)$ & $1894.7(3)$ & $5522.2(5)$ \\
\hline$Z$ & 2 & 2 & 4 \\
\hline$\rho_{\text {calc }} \mathrm{g} \mathrm{cm}^{-3}$ & 1.809 & 1.775 & 1.590 \\
\hline$\mu / \mathrm{mm}^{-1}$ & 1.579 & 1.558 & 1.109 \\
\hline$F(000)$ & 998.0 & 988.0 & 2620.0 \\
\hline Crystal size $/ \mathrm{mm}^{3}$ & $0.55 \times 0.15 \times 0.17$ & $0.45 \times 0.29 \times 0.16$ & $0.43 \times 0.27 \times 0.09$ \\
\hline Radiation & $\operatorname{MoK} \alpha(\lambda=0.71073)$ & $\operatorname{MoK} \alpha(\lambda=0.71073)$ & $\operatorname{MoK} \alpha(\lambda=0.71073)$ \\
\hline $2 \theta$ range for data collection $/^{\circ}$ & 4.236 to 51.362 & 4.624 to 51.36 & 4.488 to 52.918 \\
\hline \multirow[t]{3}{*}{ Index ranges } & $-14 \leq h \leq 14$ & $-12 \leq h \leq 12$ & $-16 \leq h \leq 16$ \\
\hline & $-14 \leq k \leq 14$ & $-16 \leq k \leq 16$ & $-17 \leq k \leq 16$ \\
\hline & $-18 \leq l \leq 18$ & $-17 \leq l \leq 17$ & $-38 \leq l \leq 38$ \\
\hline Reflections collected & 176958 & 139558 & 178794 \\
\hline Independent reflections & $7120\left[R_{\mathrm{int}}=0.0418, R_{\mathrm{sigma}}=0.0106\right]$ & $7199\left[R_{\mathrm{int}}=0.0348, R_{\text {sigma }}=0.0100\right]$ & $11348\left[R_{\mathrm{int}}=0.0522, R_{\mathrm{sigma}}=0.0186\right]$ \\
\hline Data/restraints/parameters & $7120 / 225 / 687$ & $7199 / 180 / 655$ & $11348 / 36 / 890$ \\
\hline Goodness-of-fit on $F^{2}$ & 1.303 & 1.289 & 1.181 \\
\hline Final $R$ indexes $[I \geq 2 \sigma(I)]$ & $R_{1}=0.0291, \mathrm{w} R_{2}=0.0614$ & $R_{1}=0.0333, \mathrm{w} R_{2}=0.0725$ & $R_{1}=0.0324, \mathrm{w} R_{2}=0.0583$ \\
\hline Final $R$ indexes [all data] & $R_{1}=0.0355, \mathrm{w} R_{2}=0.0685$ & $R_{1}=0.0390, \mathrm{w} R_{2}=0.0786$ & $R_{1}=0.0433, \mathrm{w} R_{2}=0.0622$ \\
\hline Largest diff. peak/hole/e $\AA^{-3}$ & $1.52 /-1.15$ & $2.09 /-1.04$ & $0.37 /-0.54$ \\
\hline
\end{tabular}




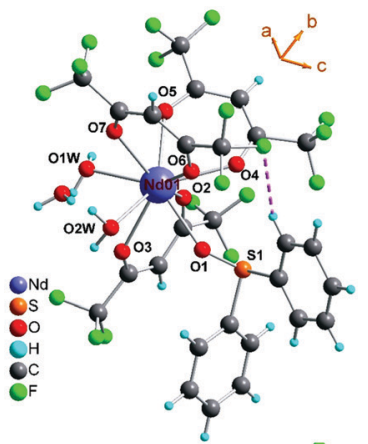

Complex 1
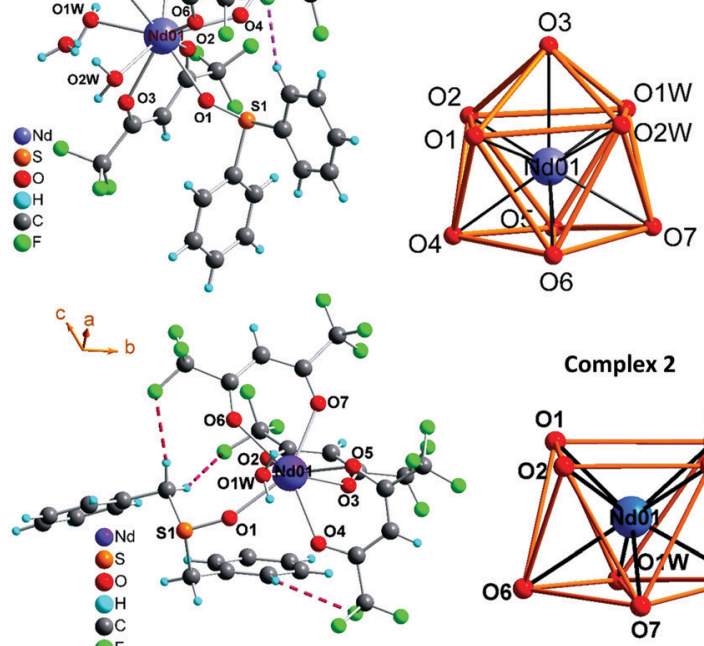

Complex 2

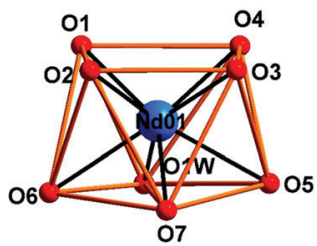

Complex 3
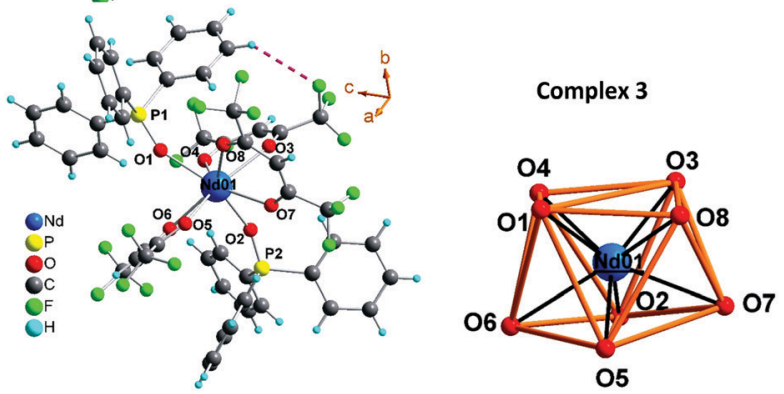

Fig. 2 Crystal structures of the complexes 1-3. Thermal ellipsoids are drawn at the $30 \%$ probability level.

given in Tables S1-S3 (ESI $\dagger$ ). In complex 1, angles $\delta_{1}$ and $\delta_{2}$ represent the planarity of the square planes, and they are 2.60 and $12.4^{\circ}$, respectively. In contrast, angles $\delta_{3}, \delta_{4}$ and $\delta_{5}$ represent the triangular faces of convex trapezoids, and they are 49.3, 54.1 and $60.6^{\circ}$, respectively. Moreover, $\varphi_{1}$ and $\varphi_{2}$ are the measure of non-planarity degree of the diagonal trapezoids, and they are 30.0 and $32.4^{\circ}$, respectively.

All these angles are close to the angles $\left(\delta_{3}=\delta_{4}=53.0^{\circ}\right.$, $\delta_{5}=59.0^{\circ}$ and $\varphi_{1}=\varphi_{2}=37.6^{\circ}$ ) of an ideal MSAP polyhedron. This indicates that the coordination polyhedron of complex 1 possesses $C_{4 \mathrm{v}}$ symmetry, with slight distortion. For complexes 2 and $3, \delta_{3}$ and $\delta_{4}$ are $59.4 / 49.3^{\circ}$ and $57.3 / 56.2^{\circ}$, respectively, with $\varphi_{1}$ and $\varphi_{2}$ being $29.9 / 28.3^{\circ}$ and $31.0 / 24.7^{\circ}$. These angles are close to the angles $\left(\delta_{3}=\delta_{4}=52.4^{\circ}\right.$ and $\left.\varphi_{1}=\varphi_{2}=24.5^{\circ}\right)$ of an ideal SAP polyhedron, indicating $D_{4 \mathrm{~d}}$ symmetry, with slight distortions. The distortions in the coordination structures of the complexes could be related to the presence of the $\mathrm{Nd}-\mathrm{O}(\mathrm{dpso} / \mathrm{dbso} / \mathrm{tppo})$ single bonds, which are very flexible and free to rotate. Moreover, a comparison between the complexes indicates that the coordination polyhedron of complex 3 (monoclinic) is relatively more symmetrical as its angles are closer to those of an ideal SAP polyhedron. The reason could be attributed to the presence of six phenyl rings of two coordinated tppo units, which have less space to rotate freely as compared to complexes $\mathbf{1}$ and $\mathbf{2}$ (triclinic), where two phenyl rings in one coordinated dpso or dbso ligand, respectively, possess more flexibility.

\section{NMR spectroscopy}

The NMR spectra of the complexes were recorded in deuterated chloroform at room temperature (Fig. 3). The assignment of the resonances due to the protons of the coordinated ligands was done on the basis of $2 \mathrm{D}^{1} \mathrm{H}-{ }^{1} \mathrm{H}$ COSY spectroscopy (Fig. S2-S4, ESI $\dagger$ ).

The NMR spectrum of complex 1 shows five well resolved signals; one due to coordinated hfpd integrating 3 protons, three due to coordinated dpso integrating 10 protons and one due to coordinated water molecules. These integration values confirm that hfpd and dpso are present in the ratio of $3: 1$ in the complex. The signal appearing at $-4.02 \mathrm{ppm}$ shows the highest upfield shift, and corresponds to the protons of the coordinated water, owing to its close proximity to the $\mathrm{Nd}$ ion. This signal is followed by the signal appearing at $4.89 \mathrm{ppm}$ corresponding to protons a (see the labelling in Scheme 1), which, in turn, show a clear COSY correlation with protons $b$ at

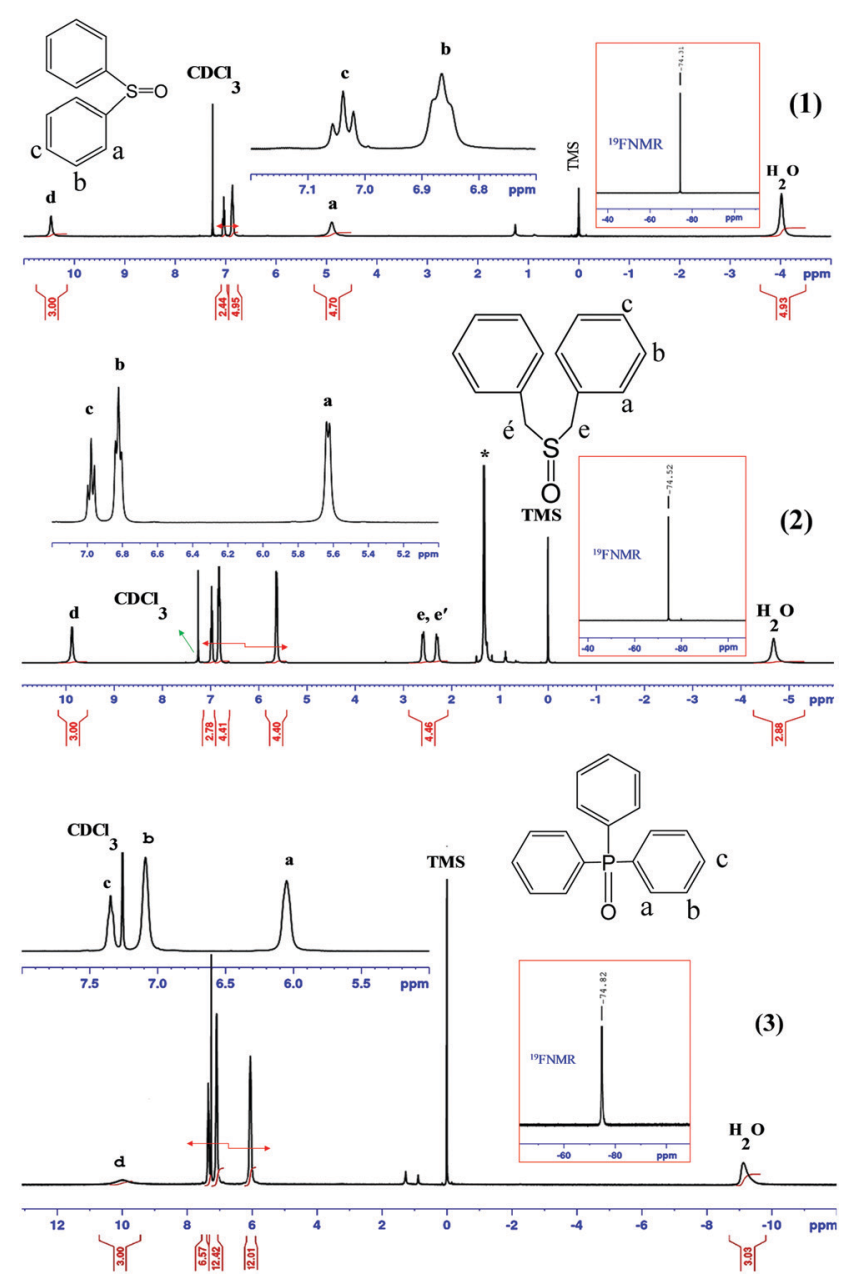

Fig. $3{ }^{1} \mathrm{H}$-NMR spectra of complexes $1-3$. Insets: ${ }^{19} \mathrm{~F}$ spectra and high resolution of ${ }^{1} \mathrm{H}-\mathrm{NMR}$. 
6.86 ppm. The signal appearing at $7.03 \mathrm{ppm}$ was COSY correlated with protons $\mathrm{b}$, and assigned to protons $\mathrm{c}$. The signal appearing at $10.46 \mathrm{ppm}$ did not show a COSY correlation with any protons, and was assigned to protons $\mathrm{d}$.

The NMR spectrum of complex 2 shows seven peaks, confirming the presence of hfpd and dbso ligands in the ratio of $3: 1$. The highest upfield shifted peak at $-4.68 \mathrm{ppm}$ was assigned again to the protons of coordinated water molecules. These protons are followed by methylene groups of the dbso ligand, which are shifted to the upfield side (at 2.29 and $2.58 \mathrm{ppm}$ ) as compared to their position in the free dbso ligand. These protons should give only one signal as observed in free dbso. However, the presence of two signals indicates that each proton of the methylene group has a different chemical environment. The COSY spectrum shows a clear correlation between these protons, and they were assigned as e and $\mathrm{e}^{\prime}$. Two strong peaks, a doublet and a triplet, appearing at 5.62 and 6.97 ppm, respectively, show a COSY correlation with a strong triplet at $6.83 \mathrm{ppm}$. This correlation clearly suggests that the two former peaks correspond to protons a and $\mathrm{c}$ and the latter peak corresponds to protons b. Like complex 1, a strong downfield shifted signal appearing at $9.87 \mathrm{ppm}$ was assigned to protons $\mathrm{d}$.

Similar to the spectra of complexes 1 and 2, the NMR spectrum of complex 3 also shows a signal due to the coordinated water molecule at $-9.13 \mathrm{ppm}$. Besides this, the spectrum of complex 3 shows four signals: three due to the two coordinated tppo ligands corresponding to 30 protons and one due to the three coordinated hfpd ligands corresponding to 3 protons. A strong peak at $6.05 \mathrm{ppm}$ shows a COSY correlation with the peak at $7.09 \mathrm{ppm}$, which in turn is COSY correlated with the peak at $7.35 \mathrm{ppm}$. The former two peaks were assigned to protons a and b, respectively, and the latter peak was assigned to protons c, while a strong signal at $10.01 \mathrm{ppm}$ was assigned to protons $\mathrm{d}$.

The ${ }^{1} \mathrm{H}$ - and ${ }^{19} \mathrm{~F}$-NMR spectra of the present complexes, in solution, show only one set of signals for protons and one signal for fluorine atoms of the three hfpd ligands. This result indicates an average pseudo-trigonal symmetry of $\left[\operatorname{Ln}(\mathrm{hfpd})_{3}\right]$ on the NMR timescale, at odds with the crystal structures, where only a two-fold axis is assumed. This suggests that the hfpd ligands at equatorial and axial positions exchange rapidly (owing to the dynamic behavior of Ln complexes in solution), and make themselves equivalent on the NMR timescale, which, therefore, leads to a dynamically averaged $C_{2 \mathrm{v}}$ symmetry for the two tppo co-ligands in complex 3. In contrast, no such symmetry is assumed in $\mathbf{1}$ (with one dpso and two water molecules as co-ligands) and 2 (with one dbso and one water molecule as co-ligands) since they do not have both co-ligands the same like the tppo ligands in complex 3 . In complex 3 , each proton on the tppo ligands shows only a single signal. This suggests a fast exchange between the coordinated and uncoordinated tppo ligands on the NMR timescale that averages the signals of the two coordinated a proton environment and the single free a proton environment (see Scheme 1 for numbering), and, therefore, produces a single observed peak. A similar phenomenon was also considered for $\mathrm{b}$ and $\mathrm{c}$ protons. The above phenomenon is different from that observed for a very similar complex,
[Ln(tta) $)_{3}$ phen], where a distorted facial "static" trigonal prism structure for the $\left[\operatorname{Ln}(\mathrm{tta})_{3}\right]$ moiety was proposed with one phen ligand placed on one side of the threefold axis of the trigonal structure.

\section{Photophysics}

The absorption spectra of the complexes, recorded in dichloromethane solution at room temperature, are reported in Fig. 4. They show a broad and intense absorption band in the range of 270-350 nm, peaking at about $305 \mathrm{~nm}$, with molar absorption coefficients of $\varepsilon_{\max }=2.13 \times 10^{4}, 2.45 \times 10^{4}$ and $1.97 \times$ $10^{4} \mathrm{M}^{-1} \mathrm{~cm}^{-1}$ for 1 to 3 , respectively. This band is slightly redshifted as compared to the positions of the free ligands (hfpd and L), which locates in between 270 and $280 \mathrm{~nm}$, suggesting the coordination of the ligands to the metal ion. The $\varepsilon$ values of the complexes are about three times that of the free hfpd ligand, confirming the coordination of three hfpd ligands together with one/two co-ligands to the metal ion.

The emission spectra of complexes 1-3 have been recorded in dichloromethane solution and in the PMMA matrix, as films, at room temperature. The complexes displayed three characteristic emission peaks of the $\mathrm{Nd}$ ion centered at 892, 1071 and 1351 nm corresponding to ${ }^{4} \mathrm{~F}_{3 / 2} \rightarrow{ }^{4} \mathrm{I}_{9 / 2},{ }^{4} \mathrm{~F}_{3 / 2} \rightarrow{ }^{4} \mathrm{I}_{11 / 2}$ and ${ }^{4} \mathrm{~F}_{3 / 2} \rightarrow$ ${ }^{4} \mathrm{I}_{13 / 2}$ transitions, respectively (Fig. 5). The quantum yield $(\phi)$ of complexes 1-3, determined in dichloromethane solutions, is $0.011,0.011$ and $0.042 \%$, respectively. These values can be compared with the ones already reported in the literature for $\left[\mathrm{Nd}\right.$ (Boditerpy) $\left.\left(\mathrm{NO}_{3}\right)_{3}\right]\left(0.016 \% \text { in } \mathrm{CH}_{2} \mathrm{Cl}_{2}\right)^{33}$ and $\left[\mathrm{Nd}(\mathrm{hfth})_{3}\right.$ bpy] $(0.072 \% \text { in toluene) })^{34}$ (Boditerpy $=4,4$-difluoro-8- $\left(2^{\prime}: 2^{\prime \prime} ; 6^{\prime \prime}: 2^{\prime \prime \prime}\right.$ terpyridin-4" -yl)-1,3,5,7-tetramethyl-2,6-diethyl-4-bora-3a,4a-diaza$s$-indacene) and hfth $=4,4,5,5,6,6,6$-heptafluoro-1-(2-thienyl) hexane-1,3-dione.

The emission lifetimes of the complexes were recorded in dichloromethane solutions at room temperature with excitation at $305 \mathrm{~nm}$ (Fig. S5, ESI $\dagger$ ). The fitting of the decay curves is in good agreement with mono-exponential behaviour. The emission lifetimes of complexes 1-3 are 1.18, 1.29 and $1.93 \mu \mathrm{s}$, respectively, which are higher than that reported for $\left[\mathrm{Nd}(\right.$ Boditerpy $\left.)\left(\mathrm{NO}_{3}\right)_{3}\right]$ $\left(0.27 \mu\right.$ s in the solid state) ${ }^{33}$ and are comparable to those reported for $\left[\mathrm{Nd}(\mathrm{hfth})_{3} \mathrm{bpy}\right](1.27 \mu \mathrm{s})^{34}$ and $\left[\mathrm{Nd}(\mathrm{PM})_{3}(\mathrm{TP})_{2}\right](2.2 \mu \mathrm{s}) .^{26}$

As this series of complexes was prepared to be used as active materials in NIR-OLEDs, their behaviour in a polymeric matrix,

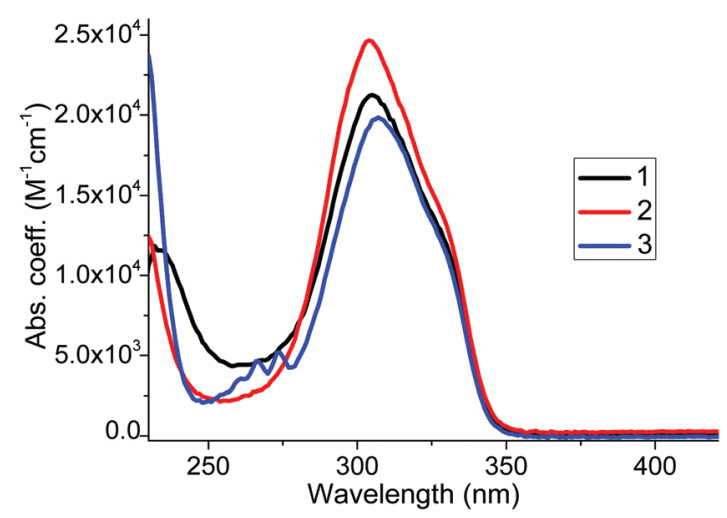

Fig. 4 Absorption spectra of the complexes in $\mathrm{CH}_{2} \mathrm{Cl}_{2}$. 


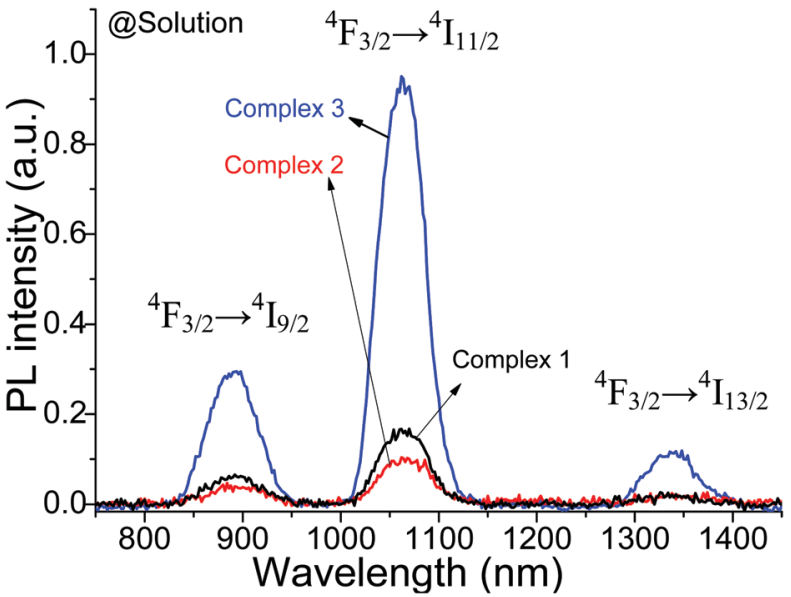

Fig. $5 \mathrm{NIR}$ emission spectra of complexes $1-3$ in $\mathrm{CH}_{2} \mathrm{Cl}_{2}$ solution; $\lambda_{\mathrm{ex}}=$ $305 \mathrm{~nm}$.

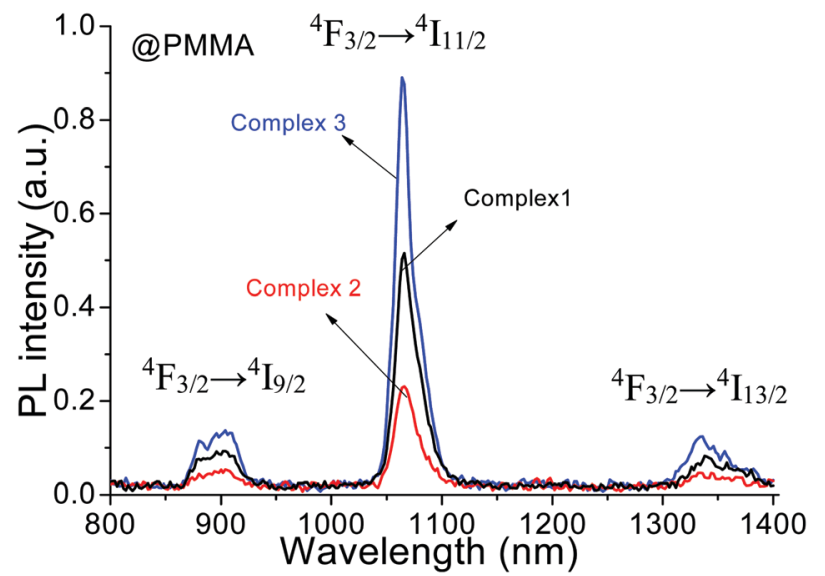

Fig. 6 Emission spectra of the PMMA doped films of complexes 1-3: $\lambda_{\text {ex }}=305 \mathrm{~nm}$.

i.e., PMMA, was tested. This environment is similar to that in the device. The PMMA doped films showed an emission pattern similar to that observed in solution (Fig. 6). Interestingly, the transitions of the complexes in liquid solutions are broader as compared to those in the PMMA matrix. For instance, the FWHM of the ${ }^{4} \mathrm{~F}_{3 / 2} \rightarrow{ }^{4} \mathrm{I}_{11 / 2}$ transitions in the solution spectra is found to be almost double (55-64 $\mathrm{nm}$ ) than that observed in the PMMA doped films $(23-25 \mathrm{~nm})$. The PMMA films of the complexes show higher luminescence efficiency as compared to the complexes in solution. This is due to the presence of the rigid PMMA matrix that can slow down the excited state deactivation pathway of the lanthanide complexes by hindering the vibrational coupling to the ground state.

Since monoclinic structures are more symmetric, they must be less luminescent as compared to the triclinic one that possesses a low symmetry structure. However, this trend is not followed for the present complexes; in turn, complex $\mathbf{3}$ with a monoclinic structure was found to be more luminescent as compared to complexes $\mathbf{1}$ and $\mathbf{2}$ with triclinic structures. Another very important reason for complex 3 to be more

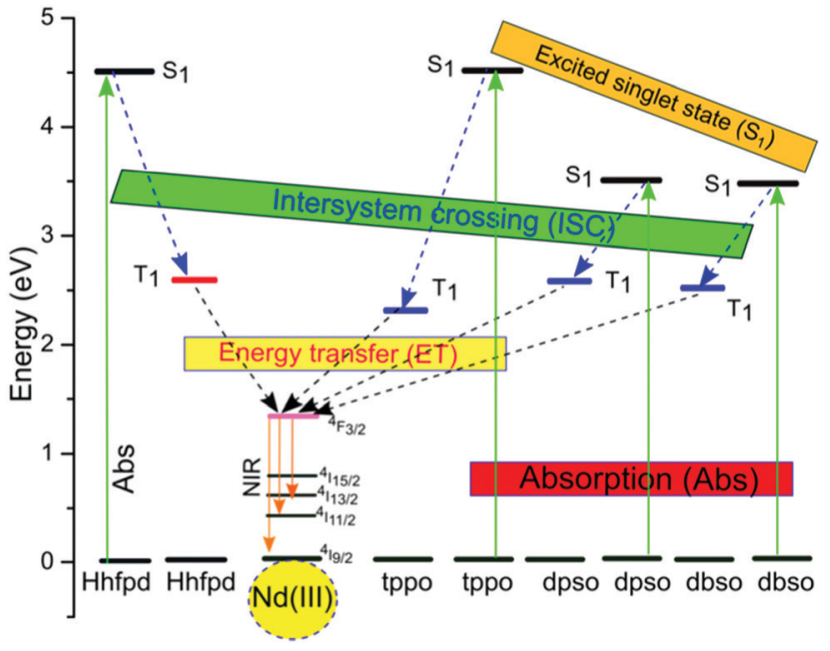

Fig. 7 Proposed energy level diagram showing the Ln ion excited state and the singlet/triplet states of $\mathrm{Hhfpd}^{11}$ and dpso/dbso/tppo sensitizers, ${ }^{15,35}$ and the energy transfer processes.

luminescent is the absence of water molecules in the coordination environment as compared to complexes $\mathbf{1}$ and $\mathbf{2}$ possessing two and one coordinated water molecules in their inner coordination spheres, respectively. The coordinated water molecules possess high frequency $\mathrm{O}-\mathrm{H}$ bonds, which have detrimental effects on the luminescence efficiency of complexes 1 and 2 since the vibrational energy of the $\mathrm{O}-\mathrm{H}$ oscillators $\left(6,900 \mathrm{~cm}^{-1} /\right.$ $0.86 \mathrm{eV}$ with vibrational quantum number, $v=2$ ) matches well with the energy gap between the lowest excited emitting state $\left({ }^{4} \mathrm{~F}_{3 / 2}\right)$ and the ground state $\left({ }^{4} \mathrm{I}_{15 / 2}\right)$ of $\mathrm{Nd}$ ions $\left(5,400 \mathrm{~cm}^{-1} /\right.$ $0.67 \mathrm{eV}$ ), leading to the quenching of the radiative transition processes. Consequently, the quantum yield of complexes 1 and 2 is 4 -fold lower as compared to complex 3. In order to understand the energy transfer mechanism in the complexes, a proposed energy level diagram of the $\mathrm{Nd}(\mathrm{III})$ ions and their corresponding organic sensitizers is shown in Fig. 7. Such vibrational excitations have been suppressed by deuteration of the $\mathrm{C}-\mathrm{H}$ bond/removal of $\mathrm{C}-\mathrm{H}$ bonds with low energy $\mathrm{C}-\mathrm{F}$ bonds to enhance the luminescence efficiency. The present complexes are good NIR emitters. This could be related to the presence of fluorinated $\beta$-diketone ligands (hfpd), which possess a relatively low lying triplet state that enhances the spectral overlap with $\mathrm{Nd}$ ions, and, therefore, leads to the optimization of the luminescence efficiency.

\section{NIR-OLEDs based on Nd complexes}

The fabrication of stable OLEDs requires thermal stability of the Ln tris $\beta$-diketonate complexes in the range from 200 to $400{ }^{\circ} \mathrm{C} .{ }^{4}$ The present $\mathrm{Nd}$ complexes showed decomposition temperatures between 200 and $320{ }^{\circ} \mathrm{C}$, which are high enough to fabricate devices based on them. Consequently, the multilayered devices with the structure $\mathrm{ITO} / \mathrm{MoO}_{3}(2 \mathrm{~nm}) / \beta$-NPB $(30 \mathrm{~nm}) / \mathrm{TcTa}: 1-3(10 \%, 20 \mathrm{~nm}) / \mathrm{TPBi}: 1-3 \quad(10 \%, 10 \mathrm{~nm}) / \mathrm{TPBi}$ $(10 \mathrm{~nm}) / \mathrm{Alq}_{3}(40 \mathrm{~nm}) / \mathrm{LiF} / \mathrm{Al}(100 \mathrm{~nm})$, were successfully fabricated. The complexes were used as emitting components in all the devices. The complexes were used as dopants in two 


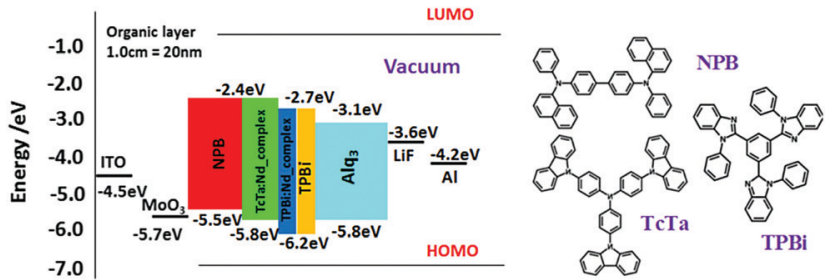

Fig. 8 Energy level diagram of devices with the structure: ITO/MoO $/ 3-\mathrm{NPB} /$ TcTa:[Nd-complexes](10\%)/TPBi:[Nd-complexes] (10\%)/TPBi/Alq $3 /$ LiF/Al.

different organic matrixes (TcTa and TBPi) in a percent ratio of 10:90 (w/w, Nd-complex:matrix), respectively, in order to efficiently transfer energy from the organic matrixes to the $\mathrm{Nd}$ complexes since the absorption spectra of the complexes show a good overlap with the emission spectra of the matrixes. Moreover, to design an optimal device, a suitable energy match between triplet states of the organic layers and their abilities to inject/transfer the electrons/holes are very important key parameters. As a result, the HOMO (highest occupied molecular orbital) and LUMO (lowest unoccupied molecular orbital) energy levels of the complexes were determined using the equation ${ }^{36,37}$

$$
E_{\mathrm{LUMO}}=-e\left(E_{\mathrm{red}}+4.4 \mathrm{eV}\right)
$$

where $E_{\text {red }}$ was determined from the intersection point of the two tangents drawn at the rising and background currents of cyclic voltammetry (CV) (Fig. S6, ESI $\dagger$ ). The sum of the singlet energy gap $\left(E_{\mathrm{g}}\right)$ and the $E_{\mathrm{LUMO}}$ energy level returns the energy

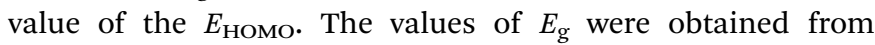
absorption spectra of the complexes as previously reported. ${ }^{38}$ The values of the HOMO and LUMO levels thus obtained for the complexes are -7.0 and $-3.6 \mathrm{eV}$, respectively. The molecular structures and the HOMO/LUMO levels of the materials used in this study are shown in Fig. 8.

Device 3 begins to work with a very low voltage $\left(V_{0}\right)$ of $6 \mathrm{~V}$, which is followed by device 2 with a $V_{0}$ of $8 \mathrm{~V}$, and, lastly, the maximum $V_{0}$ value was shown by device 1 at $10 \mathrm{~V}$. A low applied voltage is a key parameter for optimisation of the device. All the devices (1-3) showed electroluminescence at 898, 1070 and $1335 \mathrm{~nm}$, with the measurements done at 0.056-0.32, 0.050.09 and $0.1-0.72 \mathrm{~mA}$ driving currents, respectively. The EL emissions observed correspond to the ${ }^{4} \mathrm{~F}_{3 / 2} \rightarrow{ }^{4} \mathrm{I}_{9 / 2},{ }^{4} \mathrm{~F}_{3 / 2} \rightarrow{ }^{4} \mathrm{I}_{11 / 2}$ and ${ }^{4} \mathrm{~F}_{3 / 2} \rightarrow{ }^{4} \mathrm{I}_{13 / 2}$ transitions of the $\mathrm{Nd}(\mathrm{III})$ ion (Fig. 9). Moreover, the FWHM values of the ${ }^{4} \mathrm{~F}_{3 / 2} \rightarrow{ }^{4} \mathrm{I}_{11 / 2}$ transitions of the devices were measured, and they are 41,38 and $26 \mathrm{~nm}$, respectively. The EL spectrum shows a similar profile to that of the PL spectrum of the complexes. This suggests that the complexes have a similar structure in the solid form as well in the respective device. Moreover, the EL spectra of the devices show very weak visible emission, which could be arising from the organic matrices. This result suggests that the singlet excitons produced in the matrices are quenched strongly by the complexes, possibly owing to efficient energy transfer from matrices to the organic ligands (dpso, dbso, tppo and hfpd) (via Förster energy transfer).

The $J-V$ and $I-V$ curves of the devices (1-3) showed a maximum irradiance of $13.0,3.70$ and $21.8 \mu \mathrm{W} \mathrm{cm} \mathrm{cm}^{-2}$ with a
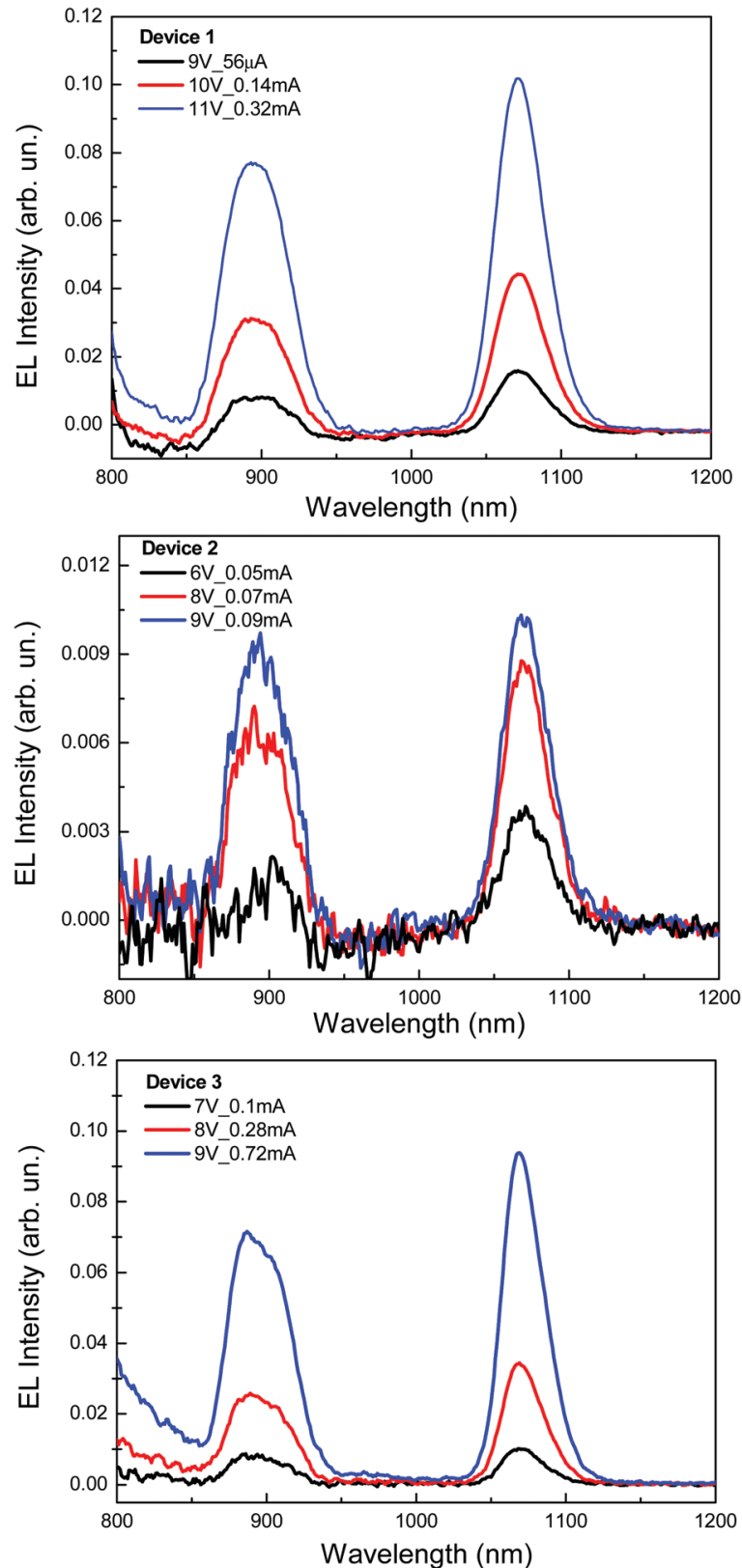

Fig. 9 Electroluminescence spectra of devices 1-3 based on complexes 1-3.

current density $(J)$ of 571,228 and $722 \mathrm{~mA} \mathrm{~cm}^{-2}$ at $16.5 \mathrm{~V}$, 13.5 and $13 \mathrm{~V}$, respectively (Fig. 10 and Table 2). Device 3 is stable up to an applied voltage of $22 \mathrm{~V}$, and it begins to degrade immediately after an applied voltage of $23 \mathrm{~V}$. In contrast, devices 1 and 2 are stable up to the applied voltages of 17 and $14 \mathrm{~V}$, respectively. Device 3 is most stable and efficient as compared to devices $\mathbf{1}$ and 2 . This could be related to the presence of tppo ligands in complex 3 , which formed a thermally stable complex with the Nd ion, and also possess good electron transport properties. The electrical performance shown by device 3 is comparable with that of other efficient Nd-complex based devices. ${ }^{24-29,31}$ Moreover, the irradiance shown by device 3 was observed at a lower voltage as compared to the reported ones, ${ }^{24-29,31}$ which indicates that device 3 is 


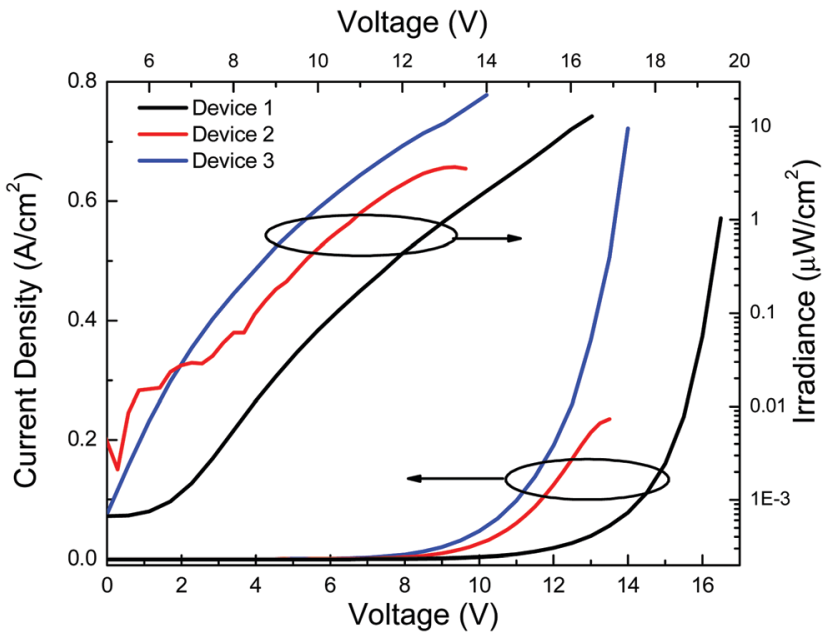

Fig. 10 Irradiance (I)-current density (J)-voltage ( $)$ curves of devices 1 -3

Table 2 Electroluminescence properties of the devices, with $\lambda_{\max }$ at $1070 \mathrm{~nm}$

\begin{tabular}{llll}
\hline & $V_{0}(\mathrm{~V})$ & $\begin{array}{l}\text { Max current } \\
\text { density }\left(\mathrm{mA} \mathrm{cm}^{-2}\right)\end{array}$ & $\begin{array}{l}\text { Max Irradiance } \\
\left.(\mu \mathrm{W} \mathrm{cm})^{-2}\right)\end{array}$ \\
\hline Device 1 & 10 & 571 & 3.7 \\
Device 2 & 8 & 228 & 13.0 \\
Device 3 & 6 & 722 & 21.8
\end{tabular}

relatively more optimized. However, the structure of the present NIR-OLEDs is, still, not fully optimised since some visible emission is observed in the EL spectra of the devices. This requires further optimization - removal of visible emission and enhancement of EL emission - of the structure of the present NIR-OLEDs to develop more efficient NIR-OLEDs based on the present complexes.

\section{Conclusion}

An in situ reaction of Hhfpd, hydrated $\mathrm{Nd}(\mathrm{III})$ chlorides, ammonium hydroxide (a base), and L (dpso, dbso, and tppo) afforded three NIR-emitting ternary neodymium tris $\beta$-diketonate complexes, $\left[\mathrm{Nd}(\mathrm{hfpd})_{3}(\mathrm{dpso})\left(\mathrm{H}_{2} \mathrm{O}\right)_{2}\right] \cdot\left(\mathrm{H}_{2} \mathrm{O}\right)(\mathbf{1}),\left[\mathrm{Nd}(\mathrm{hfpd})_{3}(\mathrm{dbso})\left(\mathrm{H}_{2} \mathrm{O}\right)\right](\mathbf{2})$ and $\left[\mathrm{Nd}(\mathrm{hfpd})_{3}(\mathrm{tppo})_{2}\right](3)$. The single crystal X-ray analysis showed that complex $\mathbf{1}$ is nona-coordinated while complexes $\mathbf{2}$ and $\mathbf{3}$ are octacoordinated, and they possess distorted square antiprismatic $\left(D_{4 \mathrm{~d}}\right)$ and monocapped square antiprism $\left(C_{4 \mathrm{v}}\right)$ geometries, respectively. NMR analysis confirmed the nona- and octa-coordinate structures of the complexes in solution. Thermogravimetric analysis showed that the complexes are thermally stable up to 200$320{ }^{\circ} \mathrm{C}$, suggesting their possible use in optoelectronic devices. Compared to complexes 1 and 2, complex 3 showed a longer luminescence lifetime and higher quantum yield. This could be ascribed to the absence of coordinated water molecules in the inner coordination sphere. In contrast to the case in solution, the PMMA doped films of the complexes showed higher luminescence efficiency. Finally, the complexes were used as emitting layers to fabricate NIR-OLEDs with the structure: $\mathrm{ITO} / \mathrm{MoO}_{3}$
$(2 \mathrm{~nm}) / \beta$-NPB $(30 \mathrm{~nm}) / \mathrm{TcTa}:[\mathrm{Nd}-\mathrm{complex}](20 \mathrm{~nm}) / \mathrm{TPBi}:[\mathrm{Nd}-$ complex] $(10 \mathrm{~nm}) / \mathrm{TPBi}(10 \mathrm{~nm}) / \mathrm{Alq}_{3}(40 \mathrm{~nm}) / \mathrm{LiF}(0.1 \mathrm{~nm}) / \mathrm{Al}$ $(100 \mathrm{~nm})$. Device 3 showed better EL performance compared to devices $\mathbf{1}$ and 2, and also comparable performance to the most efficient Nd complex based devices reported so far.

\section{Experimental section}

\section{Materials and methods}

Commercially available $\mathrm{Nd}_{2} \mathrm{O}_{3}(99.9 \%)$ from Aldrich was used without further purification. The oxide was converted to the corresponding chloride $\mathrm{NdCl}_{3} \cdot n \mathrm{H}_{2} \mathrm{O},(n=6-7)$. The Hhfpd, dbso, dpso and tppo ligands were purchased from Merck. The solvents used in this study were either of AR or spectroscopic grade. Elemental analyses were performed on a Flesh EA instrument (Thermo Electron, Model 1112). The infrared spectrum was recorded on a PerkinElmer Spectrum 2 spectrophotometer in the range of $4000-400 \mathrm{~cm}^{-1}$. The NMR spectra of the ligands and the complexes in $\mathrm{CDCl}_{3}$ were recorded, with TMS as a reference, on a BRUKER AVANCE II 400 NMR Spectrometer. The electronic spectra of the complexes were recorded on a HP Hewlett Packard 8452 A Diode array spectrophotometer, with the samples contained in a $1 \mathrm{~cm}^{3}$ stoppered quartz cell of $1 \mathrm{~cm}$ path length in the concentration range between $1 \times 10^{-5}$ and $1 \times 10^{-3} \mathrm{M}$. The photoluminescence spectra were recorded on a Model Quanta Master spectrometer using a $150 \mathrm{~W}$ xenon lamp as the excitation source and an InGaAs photomultiplier tube as a detector. The relative quantum yields were measured in dichloromethane at room temperature with respect to a reference solution of $\left[\mathrm{Ru}(\mathrm{bpy})_{3}\right] \mathrm{Cl}_{2}\left(\phi_{\mathrm{r}}=0.028\right)$, with $20 \%$ error. ${ }^{39}$ The concentrations of the solutions were taken as $5 \times 10^{-5} \mathrm{M}$ for the luminescence spectra and the lifetime measurements. The luminescence lifetimes were obtained by using a Jobin-Yvon IBH 5000F TCSPC apparatus equipped with a TBX Picosecond Photon Detection Module and Nano LED/Spectra LED pulsed excitation sources. The current-luminance-voltage properties were measured by using a Keithley source measurement unit (Keithley 2400) and Newport power meter Model 1936-C.

\section{Synthesis of complexes}

A single step reaction was adopted for the synthesis of all complexes. $0.33 \mathrm{~mL}$ of an aqueous solution of $\mathrm{NH}_{4} \mathrm{OH}$ $(0.082 \mathrm{~g}, 4.8 \mathrm{mmol})$ was added to an ethanolic solution of Hhfpd (1.0 g, $4.8 \mathrm{mmol}$ ), and the mixture was stirred for 20 minutes in a $100 \mathrm{~mL}$ beaker. To this mixture, $20 \mathrm{~mL}$ of an ethanolic solution each of the co-ligands L (dpso, $0.324 \mathrm{~g}$, $1.6 \mathrm{mmol}$; dbso, 0.37, $1.6 \mathrm{mmol}$; tppo, $0.45 \mathrm{~g}, 1.6 \mathrm{mmol}$ ) and of $\mathrm{NdCl}_{3} \cdot 6 \mathrm{H}_{2} \mathrm{O}(0.57 \mathrm{~g}, 1.6 \mathrm{mmol})$ was added. The reaction mixture immediately produced a white precipitate and was stirred for $6 \mathrm{hrs}$. The solution was left for slow evaporation at room temperature, which after three days gave blue colour crystals that were then washed with ethanol and chloroform, and finally recrystallized from the ethanol/hexane solution.

(1) $\left[\mathrm{Nd}(\mathrm{hfpd})_{3}(\mathrm{dpso})\left(\mathrm{H}_{2} \mathrm{O}\right)_{2}\right] \cdot \mathrm{H}_{2} \mathrm{O}$, Colour (blue). Yield (80\%). Elemental analysis: anal. calcd for $\mathrm{C}_{27} \mathrm{H}_{17} \mathrm{~F}_{18} \mathrm{NdO}_{9} \mathrm{~S} \cdot \mathrm{H}_{2} \mathrm{O}$ : 
C, 32.00; H, 1.66; S, 3.11. Found: C, 32.60; H, 1.8; S, 3.2. ${ }^{1} \mathrm{H}$ NMR (400 MHz, $\mathrm{CDCl}_{3}, 300 \mathrm{~K}$ ): $(\delta) \mathrm{ppm}, 10.46$ (bs, $3 \mathrm{H}_{\mathrm{d}}$, hfpd), 7.03 (t, 2 $\left.\mathrm{H}_{\mathrm{c}}, \mathrm{dpso}\right), 6.86$ (bt, $4 \mathrm{H}_{\mathrm{b}}$, dpso), 4.89 (bs, $4 \mathrm{H}_{\mathrm{a}}$, dpso) and -4.02 (bs, coordinated $\mathrm{H}_{2} \mathrm{O}$ ). ${ }^{19} \mathrm{~F}$ NMR (376 $\mathrm{MHz}, \mathrm{CDCl}_{3}$, $300 \mathrm{~K}):(\delta) \mathrm{ppm},-74.31$. FT-IR data $\left(\mathrm{cm}^{-1}\right): 3650(\mathrm{w}), 3521(\mathrm{w})$, 3140(w), 1653(m), 1559(w), 1530(w), 1494(s), 1134(s), 983(m), 796(m), 748(w), 686(w), 654(s), 584(m), 545(w), 519(w), 474(w). $\mathrm{mp}, 85{ }^{\circ} \mathrm{C}$.

(2) $\left[\mathrm{Nd}(\mathrm{hfpd})_{3}(\mathrm{dbso})\left(\mathrm{H}_{2} \mathrm{O}\right)\right]$, Colour (blue). Yield (83\%). Elemental analysis: anal. calcd for $\mathrm{C}_{29} \mathrm{H}_{19} \mathrm{~F}_{18} \mathrm{NdO}_{8} \mathrm{~S}$ : C, 34.32; $\mathrm{H}$, 1.87; S, 3.15. Found: C, 34.30; H, 1.90; S, 3.32. ${ }^{1} \mathrm{H}$ NMR $\left(400 \mathrm{MHz}, \mathrm{CDCl}_{3}, 300 \mathrm{~K}\right):(\delta) \mathrm{ppm}, 9.87$ (bs, $3 \mathrm{H}_{\mathrm{d}}$, hfpd), 6.97 (t, $\left.2 \mathrm{H}_{\mathrm{c}}, \mathrm{dbso}\right), 6.83\left(\mathrm{t}, 4 \mathrm{H}_{\mathrm{b}}, \mathrm{dbso}\right), 5.62\left(\mathrm{~d}, 4 \mathrm{H}_{\mathrm{a}}, \mathrm{dbso}\right), 2.58$ (d, $2 \mathrm{H}_{\mathrm{e}}$, dbso), 2.29 (d, $2 \mathrm{H}_{\mathrm{e}}$, dbso) and -4.68 (bs, coordinated $\left.\mathrm{H}_{2} \mathrm{O}\right) .{ }^{19} \mathrm{~F}$ NMR $\left(376 \mathrm{MHz}, \mathrm{CDCl}_{3}, 300 \mathrm{~K}\right):(\delta) \mathrm{ppm},-74.52$. FT-IR data $\left(\mathrm{cm}^{-1}\right)$ : $3596(\mathrm{w}), 3417(\mathrm{w}), 1645(\mathrm{~s}), 1555(\mathrm{w}), 1533(\mathrm{w})$, $1474(\mathrm{~m}), 1250(\mathrm{~s}), 1137(\mathrm{~s}), 999(\mathrm{~m}), 802(\mathrm{~m}), 740(\mathrm{w}), 705(\mathrm{w})$, 658(s), 582(s), 526(w), 476(w). mp, $102{ }^{\circ} \mathrm{C}$.

(3) $\left[\mathrm{Nd}(\mathrm{hfpd})_{3}(\mathrm{tppo})_{2}\right]$, Colour (blue). Yield (43\%). Elemental analysis: anal. calcd for $\mathrm{C}_{51} \mathrm{H}_{33} \mathrm{~F}_{18} \mathrm{NdO}_{8} \mathrm{P}_{2}$ : C, 46.29; H, 2.49; $\mathrm{N}, 4.68$. Found: $\mathrm{C}, 46.32 ; \mathrm{H}, 2.53 ; \mathrm{P}, 4.61 .{ }^{1} \mathrm{H} \mathrm{NMR}(400 \mathrm{MHz}$, $\mathrm{CDCl}_{3}, 300 \mathrm{~K}$ ): $(\delta) \mathrm{ppm}, 10.01$ (bs, $3 \mathrm{H}_{\mathrm{d}}$, hfpd), 7.35 (bs, $6 \mathrm{H}_{\mathrm{c}}$, tppo), 7.09 (bs, $12 \mathrm{H}_{\mathrm{b}}$, tppo), 6.05 (bs, $12 \mathrm{H}_{\mathrm{a}}$, tppo) and -9.13(bs, coordinated $\left.\mathrm{H}_{2} \mathrm{O}\right) .{ }^{19} \mathrm{~F}$ NMR $\left(376 \mathrm{MHz}, \mathrm{CDCl}_{3}, 300 \mathrm{~K}\right):(\delta) \mathrm{ppm}$, -74.82. FT-IR data ( $\left.\mathrm{cm}^{-1}\right)$ : 1650(s), $1482(\mathrm{w}), 1438(\mathrm{w}), 1555(\mathrm{w})$, 1524 (w), 1248 (s), 1140 (s), 1090 (w), 1027 (w), 998(w), 795 (w), $724(\mathrm{~m}), 693(\mathrm{~m}), 657(\mathrm{~m}), 583(\mathrm{~m}), 538(\mathrm{~s}), 457(\mathrm{w}), 415(\mathrm{w}) . \mathrm{mp}$, $115{ }^{\circ} \mathrm{C}$.

\section{Single crystal X-ray diffraction}

The single crystal X-ray diffraction data of the complexes were collected at room temperature on a Bruker D8 Venture diffractometer equipped with a Photon $100 \mathrm{CMOS}$ detector and using MoK $\alpha$ radiation $(0.71073 \AA$ ) from an INCOATEC micro-focus source. Final lattice parameter values and integrated intensities were obtained using SAINT software (Bruker, 2015), ${ }^{40}$ and a multi-scan absorption correction was applied with SADABS. ${ }^{41}$ The structure was solved by direct methods using Intrinsic Phasing implemented in SHELXT. ${ }^{42}$ The model was refined by applying the full-matrix least-squares method using SHELXL-12 ${ }^{41}$ with OLEX2 software. ${ }^{43}$ All nonhydrogen atoms were refined with anisotropic displacement parameters. Hydrogen atoms were placed at calculated positions and refined using a riding model. The crystallographic data have been deposited with the Cambridge Crystallographic Data Centre. CCDC reference numbers 1881479-1881481 contain the supplementary crystallographic data for this paper. $\dagger$

\section{Device fabrication}

The OLEDs were assembled using heterojunctions containing a multilayer structure using $\beta$-NPB $\left(N, N^{\prime}\right.$-bis(naphtalen-2-yl)- $N, N^{\prime}$ bis(phenyl)-benzidine) as a hole-transporting layer and the Nd complexes as emitting layers. TcTa (Tris(4-carbazoyl-9ylphenyl)amine) and TPBi (2,2', $2^{\prime \prime}$-(1,3,5-benzinetriyl)-tris(1phenyl-1- $H$-benzimidazole)) were used as the organic matrices to promote the energy transfer to $\mathrm{Nd}$ complexes. $\mathrm{Alq}_{3}$ (tris(8-hydroxyquinolinato)aluminium) was used as an electron-transporting layer. Finally, a $100 \mathrm{~nm}$ thick aluminum film was deposited as a cathode onto a $0.1 \AA$ A layer of LiF. For the multilayered device, the emitting layer was prepared by co-evaporation of TcTa (matrix) and the Nd complex (dopant) from two individual thermal sources. This was followed by another co-evaporated layer of the complex doped into TPBi as a second matrix. The concentration of the complex in both matrixes was taken as the same. All the different layers of the device were sequentially deposited in a high vacuum environment by thermal evaporation onto ITO substrates with a sheet resistance of $15 \Omega$ square $^{-1}$. The ITO substrate was initially cleaned using ultrasonication using a detergent solution followed by toluene degreasing and then it was cleaned again using ultrasonication with pure isopropyl alcohol. Finally, the substrate was dried using nitrogen gas. The base pressure was $6.6 \times 10^{-5} \mathrm{~Pa}$, whereas during the evaporation process, the pressure was $\sim 10^{-4} \mathrm{~Pa}$. The deposition rates for organic compounds were in the range of 0.3 to $2 \AA \mathrm{s}^{-1}$. The layer thickness was controlled in situ through a quartz crystal monitor and confirmed with profilometer measurement. The fabricated device had an active area of around $3 \mathrm{~mm}^{2}$ and was operated at forward bias voltage with ITO as the positive electrode and $\mathrm{Al}$ as the negative one.

\section{Thin film preparation}

The complex and PMMA matrix were mixed in the ratio of $1: 10$ in dichloromethane solution. The mixed solution was kept overnight for the evaporation of the solvent, which gave uniform thin films of the PMMA doped complexes.

\section{Conflicts of interest}

There are no conflicts to declare.

\section{Acknowledgements}

The authors are grateful to the Brazilian agencies CAPES, CNPq, FAPERJ, and INEO, the Italian CNR project PHEEL, and the EC project H2020-MSCA-IF-2016 no. 749287 WHITELIGHT for their financial support. Z. Ahmed is a recipient of a CAPES/ PNPD postdoctoral fellowship.

\section{References}

1 J. C. G. Bunzli, Chem. Rev., 2010, 110, 2729-2755.

2 K. Kuriki, Y. Koike and Y. Okamoto, Chem. Rev., 2002, 102, 2347-2356.

3 M. A. Katkova and M. N. Bochkarev, Dalton Trans., 2010, 39, 6599-6612.

4 J. Kido and Y. Okamoto, Chem. Rev., 2002, 102, 2357-2368. 5 L. N. Sun, H. J. Zhang, Q. G. Meng, F. Y. Liu, L. S. Fu, C. Y. Peng, J. B. Yu, G. L. Zheng and S. B. Wang, J. Phys. Chem. B, 2005, 109, 6174-6182.

6 Y. Hasegawa, M. Iwamuro, K. Murakoshi, Y. Wada, R. Arakawa, T. Yamanaka, N. Nakashima and S. Yanagida, Bull. Chem. Soc. Jpn., 1998, 71, 2573-2581. 
7 Y. Hasegawa, Y. Kimura, K. Murakoshi, Y. Wada, J. H. Kim, N. Nakashima, T. Yamanaka and S. Yanagida, J. Phys. Chem., 1996, 100, 10201-10205.

8 Y. Hasegawa, K. Murakoshi, Y. Wada, J. H. Kim, N. Nakashima, T. Yamanaka and S. Yanagida, Chem. Phys. Lett., 1996, 260, 173-177.

9 S. Yanagida, Y. Hasegawa and Y. Wada, J. Lumin., 2000, 87-9, 995-998.

10 D. Mara, F. Artizzu, P. F. Smet, A. M. Kaczmarek, K. Van Hecke and R. Van Deun, Chem. - Eur. J., 2019, 25, 15944-15956.

11 S. V. Eliseeva, D. N. Pleshkov, K. A. Lyssenko, L. S. Lepnev, J. C. G. Bunzli and N. P. Kuzmina, Inorg. Chem., 2011, 50, 5137-5144.

12 K. Yanagisawa, T. Nakanishi, Y. Kitagawa, T. Seki, T. Akama, M. Kobayashi, T. Taketsugu, H. Ito, K. Fushimi and Y. Hasegawa, Eur. J. Inorg. Chem., 2015, 4769-4774.

13 Y. X. Zheng, J. Lin, Y. J. Liang, Q. Lin, Y. N. Yu, Q. G. Meng, Y. H. Zhou, S. B. Wang, H. Y. Wang and H. J. Zhang, J. Mater. Chem., 2001, 11, 2615-2619.

14 K. Binnemans, in Handbook on the Physics and Chemistry of Rare Earths, ed. K. A. Gschneidner, J.-C. G. Bünzli and V. K. Pecharsky, Elsevier, 2005, vol. 35, pp. 107-272.

15 Z. Ahmed, R. E. Aderne, J. Kai, H. I. P. Chavarria and M. Cremona, Thin Solid Films, 2016, 620, 34-42.

16 Z. Ahmed, R. E. Aderne, J. Kai, J. Resende and M. Cremona, Polyhedron, 2016, 117, 518-525.

17 Z. Ahmed, R. E. Aderne, J. Kai, J. Resende, H. I. PadillaChavarria and M. Cremona, RSC Adv., 2017, 7, 18239-18251.

18 E. S. Andreiadis, N. Gauthier, D. Imbert, R. Demadrille, J. Pecaut and M. Mazzanti, Inorg. Chem., 2013, 52, 14382-14390.

19 S. Biju, N. Gopakumar, J. C. G. Bunzli, R. Scopelliti, H. K. Kim and M. L. P. Reddy, Inorg. Chem., 2013, 52, 8750-8758.

20 J. C. G. Bunzli, Coord. Chem. Rev., 2015, 293, 19-47.

21 P. Martin-Ramos, C. Coya, V. Lavin, I. R. Martin, M. R. Silva, P. S. P. Silva, M. Garcia-Velez, A. L. Alvarez and J. Martin-Gil, Dalton Trans., 2014, 43, 18087-18096.

22 Y. C. Miranda, L. Pereira, J. H. P. Barbosa, H. F. Brito, M. Felinto, O. L. Malta, W. M. Faustino and E. E. S. Teotonio, Eur. J. Inorg. Chem., 2015, 3019-3027.

23 N. B. D. Lima, S. M. C. Goncalves, S. A. Junior and A. M. Simas, Sci. Rep., 2013, 3, 2395.

24 A. O'Riordan, E. O'Connor, S. Moynihan, P. Nockemann, P. Fias, R. Van Deun, D. Cupertino, P. Mackie and G. Redmond, Thin Solid Films, 2006, 497, 299-303.
25 A. O'Riordan, R. Van Deun, E. Mairiaux, S. Moynihan, P. Fias, P. Nockemann, K. Binnemans and G. Redmond, Thin Solid Films, 2008, 516, 5098-5102.

26 Z. F. Li, J. B. Yu, L. Zhou, R. P. Deng and H. J. Zhang, Inorg. Chem. Commun., 2009, 12, 151-153.

27 M. A. Katkova, A. P. Pushkarev, T. V. Balashova, A. N. Konev, G. K. Fukin, S. Y. Ketkov and M. N. Bochkarev, J. Mater. Chem., 2011, 21, 16611-16620.

28 H. B. Wei, G. Yu, Z. F. Zhao, Z. W. Liu, Z. Q. Bian and C. H. Huang, Dalton Trans., 2013, 42, 8951-8960.

29 A. Shahalizad, A. D’Aléo, C. Andraud, M. H. Sazzad, D.-H. Kim, Y. Tsuchiya, J.-C. Ribierre, J.-M. Nunzi and C. Adachi, Org. Electron., 2017, 44, 50-58.

30 Q. Liu, S. Zhang, K. Du, W. Li, Q. Yin and P.-j. Cai, J. Fluorine Chem., 2018, 212, 161-165.

31 Z. Ahmed and K. Iftikhar, Polyhedron, 2015, 85, 570-592.

32 J. B. Lu, K. H. Yu, H. Y. Wang, J. F. He, G. H. Cheng, C. Y. Qin, J. M. Lin, W. Wei and B. Peng, Opt. Mater., 2008, 30, 1531-1537.

33 R. F. Ziessel, G. Ulrich, L. Charbonniere, D. Imbert, R. Scopelliti and J. C. G. Bunzli, Chem. - Eur. J., 2006, 12, 5060-5067.

34 L. N. Sun, J. B. Yu, G. L. Zheng, H. J. Zhang, Q. G. Meng, C. Y. Peng, L. S. Fu, F. Y. Liu and Y. N. Yu, Eur. J. Inorg. Chem., 2006, 3962-3973.

35 H. Xin, M. Shi, X. C. Gao, Y. Y. Huang, Z. L. Gong, D. B. Nie, H. Cao, Z. Q. Bian, F. Y. Li and C. H. Huang, J. Phys. Chem. B, 2004, 108, 10796-10800.

36 L. Leonat, G. Sbarcea and I. V. Branzoi, UPB. Sci. Bull., Series $B, 2013,75,111-118$.

37 L. Micaroni, F. Nart and I. Hümmelgen, J. Solid State Electrochem., 2002, 7, 55-59.

38 J. P. McKelvey, Solid state and semiconductor physics, Harper \& Row, 1966.

39 M. Montalti, A. Credi, L. Prodi and M. T. Gandolfi, Handbook of Photochemistry, CRC Press, Boca Raton, 2006, ch. 10, pp. 561-581.

40 Bruker, APEX3 and SAINT, Bruker AXS Inc., Madison, Wisconsin, USA, 2015.

41 L. Krause, R. Herbst-Irmer, G. M. Sheldrick and D. Stalke, J. Appl. Crystallogr., 2015, 48, 3-10.

42 G. M. Sheldrick, Acta Crystallogr., Sect. C: Struct. Chem., 2015, 71, 3-8.

43 O. V. Dolomanov, L. J. Bourhis, R. J. Gildea, J. A. K. Howard and H. Puschmann, J. Appl. Crystallogr., 2009, 42, 339-341. 